\title{
Evaluation of Potential Risks to Human Health and Ecosystems During Exposure to Discarded Laboratory Chemical Mixtures by In Vitro Multimodel Approach
}

\author{
Chiara Scanarotti, ${ }^{1, *}$ Stefania Vernazza, ${ }^{1, *}$ Sara Tirendi, ${ }^{1,2}$ Daniela Calzia, ${ }^{3}$ Susanna Alloisio, ${ }^{4,5}$ \\ Antonio Novellino, ${ }^{4,5}$ Isabella Panfoli, ${ }^{3, \dagger}$ and Anna M. Bassi ${ }^{1,2, \uparrow}$
}

\begin{abstract}
Introduction: The toxicity of inorganic and organic mixtures (CER $160506^{*}$ ), which derive from analytical laboratory waste, being often unstable, represents a relevant issue for their toxicological interactions.

Materials and Methods: In compliance with the 3Rs policy adopted by the European Commission, a multimodel in vitro approach was set up. Toxicity and the proinflammatory potential of such mixtures were evaluated on human endothelial, epithelial cell lines (human endothelial cells from umbilical cord [HECV] and cervical cancer cells derived from Henrietta Lacks [HeLa]) and 3D-human-epidermis reconstructed model. Moreover, the effects of inorganic and organic mixtures on cellular bioenergetics and neuronal network were evaluated in terms of adenosine triphosphate (ATP) synthetic ability by rod outer segment (OS) disk and spontaneous electrical activity of rat cortical networks.

Results: Inorganic mixture was more effective than the organic one in reducing viability indexes of both human cell lines. In HeLa, expression of tumor necrosis factor-alpha gene was positively modulated by both mixtures, while the inorganic mixture reduced interleukin-18 gene levels and organic one lowered Hsp70 stress response gene. Dermal corrosion and irritation testing on a commercial 3D-human-epidermis reconstructed model showed a corrosive and irritant potential of inorganic mixture only. In addition, this latter impaired cellular bioenergy, in terms of ATP synthesis by purified rod OSs. Moreover, both mixtures exerted harmful effects on the spontaneous electrophysiology activity of rat neuronal networks, by means of microelectrode array-based platforms.

Discussion: Obtained data evidenced that both mixtures can be potentially harmful to workers.

Conclusion: This in vitro multimodel approach could be a useful starting tool for the prediction of the potential risk to humans and ecosystems.
\end{abstract}

Keywords: bioenergy, chemical mixtures, neural network toxicity, skin irritation/corrosion, toxicity.

\section{Introduction}

$\mathbf{T}$ HE DISCOVERY OF new approaches, which minimize the use of animals in research, while trying to overcome the limitations, is being given serious consideration and, therefore, in vitro testing procedures are important alternative testing methods for toxicity that meet the criteria of 3 Rs. $^{1}$
The assessment of human health risks requires the identification and integration of information on the health hazards related to the exposure of a chemical compound and the relationships between exposure, dose, and adverse outcome effects (AOE). The development of risk-assessment strategies for hazardous waste is an emerging issue in the European Union and the European Chemical Agency is applying the

\footnotetext{
${ }^{1}$ General Pathology Section, Laboratory of Analysis and Research in Physiopathology (LARF), Department of Experimental Medicine, University of Genoa, Genoa, Italy.

${ }^{2}$ Inter-University Center for the Promotion of the 3Rs Principles in Teaching \& Research (Centro 3R), Genoa, Italy.

${ }^{3}$ Department of Pharmacy-DIFAR-Biochemistry Lab., University of Genoa, Genoa, Italy.

${ }_{5}^{4}$ ETT S.p.A., Genoa, Italy.

${ }^{5}$ Institute of Biophysics, National Research Council, Genoa, Italy.

*These authors contributed equally to this work.

${ }^{\dagger}$ These authors contributed equally to this work.

(c) Chiara Scanarotti et al. 2020; Published by Mary Ann Liebert, Inc. This Open Access article is distributed under the terms of the Creative Commons License (http://creativecommons.org/licenses/by/4.0), which permits unrestricted use, distribution, and reproduction in any medium, provided the original work is properly cited.
} 
recently issued REACH Directive (Regulation 1357/2014/ EU; Decision 2014/955/EU).

Till today, the evaluation of the biological potential of chemical mixtures may not be reliable because little is known about the AOE of the cumulative exposure to a mixture of toxic substances ${ }^{2,3}$ produced from both industrial and laboratory waste. While a toxicological database exists for each single chemical included in a mixture, relevant risk assessment of the main contaminant mixtures is lacking even though there is the risk characterization of single substances. Mixtures may contain unknown components that can form, due to chemical reactions, new compounds. However, it is now known that the resulting toxicity risks due to the additive or synergistic effects of compounds can be more harmful to human health compared with those of a single chemical. ${ }^{4}$ In fact, chronic low exposure to some persistent chemicals, such as metals or lipophilic compounds, results in their accumulation in human tissues, which can contribute to the development of several diseases, such as cancer, neurodegeneration, cardiovascular disorder, and metabolic dysfunctions. ${ }^{5,6}$ Another pressing aspect is the that nanoparticles, many of which are metal/organic mixtures, do carry biological hazard. The multicomponent mixtures display joint toxicity, which can be higher than the individual toxic effect of the most potent compound present therein, regardless of its specific chemical composition. ${ }^{7,8}$

Either industrial or laboratory waste is composed of complex mixtures of very high concern. Their chemical composition can cause harm, illness, and even death through different mechanisms both in humans who are exposed to such waste during their work activities, and in other life forms when mismanaged or released into the environment. For this reason, on June 1, 2015, the European legislation, concerning the industrial/laboratory waste hazardous properties, came into force, with an obligation to provide chemical and toxicological properties of these wastes (EU Regulation 1357/2014-and EU Decision 955/2014). Routinely, single chemicals from laboratory waste, either organic or inorganic, are poured into containers that are stored in the laboratory, and then, in accordance with the Directive UE 2016/1179, the samples of which are analyzed at least once a year to allow for their correct disposal (as required by the Italian Ministerial Decree-MD 27.9.2010, later modified by the MD 24.6.2015). During this period, it should be noted that the composition of the mixture, both in quantitative and qualitative terms, could well have undergone a change.

Although, as required by safety rules, the involved personnel are subject to safety training and have access to chemical safety information, all the cited steps are open to potential hazards for both humans and the environment. However, intentionally prepared mixtures are covered by the cited CLP Regulation and, since June 1, 2015, companies are obliged to reclassify their mixtures.

In 2014, the Joint Research Center of the European Commission (EC) drew up the Regulatory Requirements and Guidance of Assessment of mixtures to highlight the methodology for risk assessment of exposure to mixtures. More recently, being aware that the composition of a mixture can often vary over time and space, mixture toxicity should be assessed, not only based on the individual components of the mixture but also on the mixture as a whole.,

To evaluate the chemical risk assessment, regulatory programs, such as REACH, promote the use of alternative ap- proaches (i.e., in silico, in vitro assay, and short-term in vivo tests) rather than traditional in vivo test methods. ${ }^{11}$

Therefore, in vitro testing can be suitable for the evaluation of hazards as well as for the risks related to both accidental and intended use of mixtures. Notably, the safety information on a single-mixture component does not reflect the effective hazard of mixture as a whole. Moreover, the composition of such mixtures, derived from routinely discarded laboratory chemicals, varies daily right up to their collection. It also highlights the fact that the potential risks of whole mixtures can be assessed simply by taking a sample during their storage using multitool approaches.

Herein, we report a preliminary multimodel in vitro approach designed in line with the $3 \mathrm{R}$ policy using different in vitro assays to verify the potential toxicity of inorganic mixture (IM) and organic mixture (OM) (i.e., the European Waste Catalogue and Hazardous Waste List CER 1605 06* associated with dangerous laboratory chemicals) from the waste of an Italian chemical analysis laboratory and environmental study (C.P.G. Lab, Cairo Montenotte, SV), in various assessment scenarios. In this study, both mixtures were examined as a whole, following the indications of the EC Decision Tree for the Risk Assessment of Mixtures for which a significant human exposure is likely/plausible and no data are available on the mixture as a whole. ${ }^{12}$ Several biological endpoints were included to perform a multimodel approach on the potential harmful effects of OM and IM accidental exposure.

Basic toxicity was evaluated in terms of neutral red uptake (NR) and 3-(4,5-dimethylthiazol-2-yl)-2,5-diphenyltetrazolium bromide (MTT) viability indexes on 2D human cervical cancer cells derived from Henrietta Lacks (HeLa) and human endothelial cells from umbilical cord (HECV) cell lines, representative of epithelial and endothelial cells respectively, after their exposure to IM and OM. In compliance with the OECD TG431 and 439, skin corrosion and irritation potentials were evaluated on commercial 3D-human-epidermisreconstructed (RHE) models, as integrated testing strategies.

Since chemicals may negatively affect cell behavior, the gene expression of two typical proinflammatory and sensitization cytokines (tumor necrosis factor alpha $[\mathrm{TNF}-\alpha]$ and interleukin [IL]-18, respectively) and of Hsp70, as a marker of cell stress response, was assessed in HeLa, a representative model of epithelium, as a first target tissue of chemical action. Cellular bioenergetics was assessed by adenosine triphosphate (ATP) synthesis in purified bovine rod outer segments (OSs). Moreover, since several lines of evidence highlight a possible link between neurological disorders and neurotoxins in the environment, neurotoxicity was investigated by microelectrode array (MEA)-based electrophysiology on cortical rat neuronal networks.

\section{Materials and Methods}

IM and OM (CER 1605 06*) were randomly collected by a certified chemical laboratory as discards (i.e., C.P.G. Analysis laboratory and environmental studies, Cairo Montenotte, Savona, Italy). Table 1 below in the form of analysis chart reports the analysis of the most relevant chemical concentrations in the two tested samples, which were $\mathrm{Cr}$ and $\mathrm{Hg}$ for $\mathrm{IM}$ and different solvents for $\mathrm{OM}$, and the acceptable limit value exposures, as stipulated by the Italian Decree-Law (DL 03.04.2006, n152, 4th section, enclosure D). 
Table 1. Analytical Chart

\begin{tabular}{llcc}
\hline $\begin{array}{l}\text { Mixture: } \\
\text { CER 16 }\end{array}$ & \multicolumn{1}{c}{$\begin{array}{c}\text { Hazardous } \\
\text { chemicals }\end{array}$} & $\begin{array}{c}\text { Concentration } \\
\text { in sample } \\
(\mathrm{mg} / \mathrm{kg})\end{array}$ & $\begin{array}{c}\text { Acceptable } \\
\text { limit value* } \\
(\mathrm{mg} / \mathrm{kg})\end{array}$ \\
\hline IM & Cr VI & $124 \pm 25$ & 1000 \\
pH 1 & Hg & $770 \pm 115.6$ & 1000 \\
OM & Acetonitrile & $<0.5$ & \\
& Dichloromethane & $35,900 \pm 7180$ & 1000 \\
& Hexane & $4500 \pm 863$ & - \\
& Toluene & $6000 \pm 1200$ & 50,000 \\
\hline
\end{tabular}

Certificate of Analysis of hazardous chemicals in IM and OM tested samples. Data provided by C.P.G Certified analysis laboratory (Cairo Montenotte, Italy).

*According to the Italian DL 03.04.2006, n152, 4th section, enclosure D.

IM, inorganic mixture; OM, organic mixture.

\section{Analysis chart}

Certificate of Analysis of hazardous chemicals in IM and OM tested samples. Data provided by the C.P.G Certified analysis laboratory (Cairo Montenotte, Italy).

All chemicals and reagents were from EuroClone S.p.A. (Milan, Italy), Gibco (Invitrogen Life Technologies, Milan, Italy), Invitrogen S.r.L. (Milan, Italy), and Sigma-Aldrich (Milan, Italy). Experimental techniques were performed within the Standard Operative Protocols of the Laboratory of Analysis and Research on Physiopathology (LARF) that, certified UNI EN ISO 9001:2008, is committed to operate according to the requirements of the Quality System and the standards on which it is based (ISO9001), and oriented to ISO15189 and BPL standards.

\section{In vitro cell models}

Human cell lines, HeLa, from cervix epidermoid carcinoma, and HECV, normal endotheliocytes from the umbilical cord (certified by STR DNA profile analysis by Biological Bank, a Core Facility of the IRCCS San Martino University Hospital-IST National Institute for Cancer Research (Genoa, Italy), were cultured at $37^{\circ} \mathrm{C}$ under $5 \%$ $\mathrm{CO}_{2}$ in Dulbecco's Modified Eagle's Medium (DMEM) plus $10 \%$ heat-inactivated fetal bovine serum. HeLa cells were chosen as a model of undifferentiated epithelioid cells, which retain limited capacity to commit to early stages of cell differentiation so as to mimic an adaptive response to stressors in epidermal cells. ${ }^{13}$ HECV cells, available from several cellular banks, were used since they share the same origin of HUVECs and are considered a bloodstream model. ${ }^{14-19}$

No antibiotic or antifungal solutions were added to standard or experimental medium to avoid any potential interference of these drugs with the cell culture. ${ }^{20-25}$

All cell cultures were found to be mycoplasma-free on regular checks with Reagent Mycoplasma Set (Euroclone). The population doubling time for HeLa and HECV was estimated to be 16 and 17 hours, respectively, by using a user friendly software (Roth V. 2006 Doubling Time Computing, Available from: www.doubling-time.com/compute.php). Based on these data, 24 hours before the experimental procedures, HeLa and HECV cells were seeded in 6- and 24-well plates (Primo ${ }^{\circledR}$ multiwell plate, Euroclone) at 15 and $4 \times 10^{4}$-cells/well, respectively, to obtain an $\sim 75 \%$ confluence. Skin corrosion and irritation tests on reconstructed 3D human skin model were conducted using $0.5 \mathrm{~cm}^{2}$ Reconstructed Human Epidermal skin substitutes (RHE/S17-EpiSkin ${ }^{\circledR}$, France). RHE consists of a threedimensional human skin model comprising a reconstructed epidermis with a functional corneum stratum and is validated as an in vitro means to assess dermal corrosion and skin irritation ${ }^{26,27}$ according to the OECD 439 and $431^{28}$ (available on: www.oecd.org/chemicalsafety/testing/ oecdguidelinesforthetestingofchemicals.htm).

\section{Experimental treatments}

For assays on 2D HeLa and HECV models, the IM and OM were dissolved in DMEM just before the experimental procedures to obtain stock solutions $(10 \%, \mathrm{v} / \mathrm{v})$ and each added to serum-free culture medium to achieve the final concentrations of $0.025,0.05,0.1,0.25,0.5$, and $1 \%(\mathrm{v} / \mathrm{v})$. Experimental procedures were carried out for 4, 12, and 24 hours. At the same time points, plates were set up with the appropriate negative controls (untreated cultures) and different doses of irritation positive control $(4,20$, and $40 \mu \mathrm{g} / \mathrm{mL}$ $\mathrm{NiSO}_{4}$ ). Each experimental condition was analyzed in two separate experiments running in triplicate. At the end of each treatment, cell viability was assessed as described below.

The skin corrosion and irritation tests were performed on Reconstructed Human Epidermis (SkinEthic ${ }^{\mathrm{TM}}$ RHE model; EpiSkin) according to the manufacturer's instruction and in compliance with OECD Test Guidelines (TGs) Nos. 431 and 439, respectively. For each test, three tissue replicates per condition were used. Briefly, $40 \pm 3 \mu \mathrm{L}\left(80 \mu \mathrm{L} / \mathrm{cm}^{2}\right)$ and $16 \pm 2 \mu \mathrm{L}\left(32 \mu \mathrm{L} / \mathrm{cm}^{2}\right)$ of IM and OM were used to evaluate their corrosion and irritation effects on the epidermal model. The exposure time was 3 and 60 minutes at room temperature for the skin corrosion protocol, whereas $42 \pm 1$ minutes at RT for the skin irritation test. Moreover, the irritation test also included a postincubation time of $42 \pm 1$ hours in SkinEthic ${ }^{\mathrm{TM}}$ growth medium.

As scheduled by corrosion and irritation assays, respectively, at the end of experimental procedures, RHE tissues were transferred to 24-well plates to then run the MTT viability test as described below.

\section{Viability assessment}

At the end of each experimental treatment, cell viability was assessed in HeLa and HECV 2D cultures by $\mathrm{NR}^{29}$ and MTT $^{30,31}$ tests. The MTT test was also performed for irritation and corrosion assays. The possible MTT direct reduction and/or interference with NR by IM and OM were checked. Both checks gave a negative outcome for all exposure times.

The optical densities (OD) of the released neutral red dye and of the dissolved formazan crystals (for MTT test) were determined spectrophotometrically at $570 \mathrm{~nm}$. The quantification of cell viability was obtained by comparing the OD of the extracts measured at $570 \mathrm{~nm}$ in percentages to the negative controls. Relative cell viability was calculated for each cell sample as a percentage of the mean of the negative control.

A chemical compound was considered toxic if the cell viability was reduced by $15 \%$ compared with the untreated cultures according to ECVAM's guidelines. 
For the RHE model, in accordance with OECD TG 431 and 439, the test material is considered to be (1) irritant to the skin if the tissue viability after exposure/postincubation is less than or equal to $50 \%$; and (2) corrosive if the viability is less than $50 \%$ and less than $15 \%$ after a 3 - and 60 -minute exposure, respectively. ${ }^{32}$

\section{Reverse transcription-polymerase chain reaction}

Primers for human TNF- $\alpha$, IL-18, Hsp70, and glyceraldehyde 3-phosphate dehydrogenase (GAPDH) were designed using the Beacon Designer 7.0 software (Premier Biosoft International, Palo Alto CA, USA) and obtained from Tib Molbiol (Genoa, Italy). The sequences of polymerase chain reaction (PCR) primers are listed in Table 2. After 24 hours of experimental procedure, the mRNA of HeLa cell IM and OM treated at $0.025,0.05$, and $0.1 \%(\mathrm{v} / \mathrm{v})$ concentrations was extracted using the RNeasyMicro Kit (Qiagen, Milan, Italy), according to the manufacturer's instructions. RNA $(1 \mu \mathrm{g})$ was reverse-transcribed into cDNAby dNTP mix (Euroclone). Amplification of cDNA by polymerase chain reaction was performed using Redy@ Taq master mix (Euroclone) and the abovementioned human primers. Results were normalized to GAPDH expression, chosen as the housekeeping gene for performing reverse transcriptionPCR on HeLa cells, on the basis of recent literature data. ${ }^{33,34}$

The amplified gene-specific PCR products were analyzed by electrophoresis on $2 \%$ agarose TBE gels stained with ethidium bromide DNA and UV visualized. Digital images were quantified by densitometric analysis by using a specific software (BIORAD GelDoc 2000; Bio-Rad Laboratories, Milan, Italy).

\section{Rod OS preparations}

Purified bovine rod OS preparations were obtained under red light at $4^{\circ} \mathrm{C}$ from 20 retinas by centrifugation (1 hour at $100,000 \mathrm{~g}$ ) on a sucrose/Ficoll continuous gradient formed by a light medium $(60 \mathrm{mM}$ sucrose, $4 \%$ Ficoll w/v, $10 \mathrm{mM}$ glucose, $10 \mathrm{mM}$ ascorbic acid, $1 \mathrm{mM} \mathrm{CaCl}_{2}$, and $20 \mathrm{mM}$ Tris- $\mathrm{HCl} \mathrm{pH} \mathrm{7.4)} \mathrm{and} \mathrm{a} \mathrm{heavy} \mathrm{Medium} \mathrm{(20 \%} \mathrm{sucrose} \mathrm{w/w}$ and $16 \%$ Ficoll w/w). ${ }^{35}$ The band corresponding to the sealed isolated OS was diluted with two volumes of $600 \mathrm{mM}$ sucrose and $200 \mathrm{mM}$ Tris- $\mathrm{HCl} \mathrm{pH} \mathrm{7.4,} \mathrm{centrifuged} \mathrm{at} 5000 \mathrm{~g}$ for 20 minutes at $4^{\circ} \mathrm{C}$, collected, and stored at $-80^{\circ} \mathrm{C}$. Before use, OSs are homogenized by diluting the OSs on ice in 1:1 (w/v) hypotonic medium (5 mM Tris- $\mathrm{HCl}$, ph 7.4-plus protease inhibitor cocktail, and ampicillin).

\section{ATP synthesis assay in rod OS}

The formation of ATP from adenosine diphosphate (ADP) and inorganic phosphate $(\mathrm{Pi})$ was assayed in purified OS as previously described. ${ }^{36}$ Such an experimental model is suitable as it expresses FoF1-ATP synthase and the electron transfer chain and conducts the oxidative phosphorylation. Moreover, the disk sidedness in the OS is similar to that of the inverted mitochondrial vesicles. For the ATP synthesis assay, rod OS homogenates $(0.04-\mathrm{mg}$ protein $/ \mathrm{mL})$ were incubated for 5 minutes at $37^{\circ} \mathrm{C}$ in $50 \mathrm{mM}$ Tris/ $\mathrm{HCl}(\mathrm{pH} \mathrm{7.4)}$, $5 \mathrm{mM} \mathrm{KCl}, 1 \mathrm{mM}$ EGTA, $5 \mathrm{mM} \mathrm{MgCl}_{2}, 0.6 \mathrm{mM}$ ouabain, $0.25 \mathrm{mM}$ di(adenosine)-5-penta-phosphate (Ap5A, adenylate kinase inhibitor), and ampicillin $(25 \mu \mathrm{g} / \mathrm{mL})$. Then, respiratory substrates $(20 \mathrm{mM}$ succinate and $0.35 \mathrm{mM} \mathrm{NADH})$, $5 \mathrm{mM} \mathrm{KH} \mathrm{KO}_{4}$, and $0.1 \mathrm{mM}$ ADP were added to induce ATP synthesis. ${ }^{37}$ When necessary, samples were preincubated for 5 minutes with $1 \%, 0.5 \%, 0.25 \%, 0.1 \%, 0.05 \%$, or $0.025 \%$ IM or OM (in the latter case, samples were also incubated for 240 minutes). The ATP concentration was measured for 1 minute in a luminometer (Lumi-Scint, Bioscan) by the luciferin/luciferase chemiluminescent method (Roche Diagnostics Corp., Indianapolis, IN). Calibration curve was obtained with ATP standard solutions (Roche Diagnostics Corp.) between $10^{-9}$ and $10^{-7} \mathrm{M}$ in the same solution of the experiments.

\section{Neural networks}

The neurotoxic effect was investigated evaluating the spontaneous electrical activity of rat cortical neuronal networks subjected to OM or IM. An integrated analysis of specific parameters, related to the global spiking activity mean firing rate (MFR) and the bursting behavior, the most important property of the dynamics of neuronal network electrical activity, was performed with the aim of better characterizing and assessing mixture-induced effects.

Neuronal networks, from rat embryonic cortical neurons at the fetal day 17 (ET17), were seeded on MEA at a density of $5 \times 10^{4} .^{38}$ Activity was recorded by the USB MEA 120 INV 2 BC System from Multi Channel Systems (MCS GmbH, Reutlingen, Germany) as previously described. ${ }^{39}$ MEA chips (60MEA200/30iR-Ti-gr; Multi Channel Systems MCS $\mathrm{GmbH}$ ) were placed into the MEA Amplifier (Gain $1000 \times)$ and the data were recorded by MC_Rack software (MCS GmbH, Version 4.4.1.0) at a sampling rate of $10 \mathrm{kHz}$. A band pass digital filter $(60-4000 \mathrm{~Hz})$ was applied to the raw signal to remove electrical background noise. Spike trains were extracted by MC_Rack spike detection: if the electric signal overcomes the spike detection threshold (i.e., 5.5 times the standard deviation of the mean square root noise), the spike is identified and recorded. The system also included a temperature controller (TC02, MCS $\mathrm{GmbH})$ that maintained the cell culture at $37^{\circ} \mathrm{C}$ during the experiments. The cells were also kept in a controlled humidified atmosphere $\left(9 \% \mathrm{CO}_{2}, 19 \% \mathrm{O}_{2}\right.$, and $\left.72 \% \mathrm{~N}_{2}\right)$ to maintain the $\mathrm{pH}$

Table 2. The Sequences of Polymerase Chain Reaction Primers

\begin{tabular}{lll}
\hline Gene & \multicolumn{1}{c}{$\mathrm{F}$} & $\mathrm{R}$ \\
\hline TNF- $\alpha$ & CTGGGATTCAGGAATGTGTG & ATTGTTCAGCTCCGTTTTCA \\
IL-18 & TCATTGACCAAGGAAATCGG & ATCCCCCAATCATCCTCTT \\
Hsp70 & GTGAAGATCTGCGTCTGGTTGG & TTTGACAACAGGCTGGTGAACC \\
GAPDH & TGAAGGTCGGAGTCAACGGATTTGGT & CATGTGGGCCATGAGGTGCACCAC
\end{tabular}

GAPDH, glyceraldehyde 3-phosphate dehydrogenase; IL-18, interleukin 18; TNF- $\alpha$, tumor necrosis factor-alpha. 
balance of the supernatant $(\mathrm{pH}$ was $7.1 \pm 0.1$ during the whole experiment). In brief, after an initial 40-minute equilibration period, continuous recordings of extracellular spontaneous electrical activity were performed following this procedure: 20 minutes in the absence of any substance (control condition) followed by 20 minutes of exposure of increasing concentrations of IM and OM (0.01\%-1\%) cumulatively administrated directly on MEA chips. The analysis was conducted by importing data (for MCS software, *.mcd files) into NeuroExplorer software (Nex Technologies) where the burst analysis tool was applied with the following burst definition parameters: bin size $=1$ second; maximum interval of starting a burst $=0.01$ second; maximum interval of ending a burst $=0.075$ second; minimum burst interval $=0.1$ second; minimum burst duration $=0.02$ second; and minimum of number of spikes in burst $=4$. Globally, five parameters were simultaneously analyzed: MFR (no. of spikes/s); mean burst rate (MBR; number. of bursts/min); mean burst duration (MBD; mseconds); percentage of spikes in burst (\% Spikes_B); and interspike intervals within a burst (MISI_B). For each parameter, the concentration/response curves, based on the mean normalized values, were obtained. Data were obtained from five to seven replicate chips derived from three different neuronal preparations. Data were averaged for the last 15 minutes and then averaged over several MEAs to create concentration curves for each mixture. To obtain the half-maximal inhibitory concentration $\left(\mathrm{IC}_{50}\right)$ values, the normalized dose/response curves were interpolated with SigmaPlot 8 (Jandel Scientific) following the formula: $Y=\max +(\min$ $-\max ) /(1+(x / \mathrm{IC} 50) n)$.

\section{Statistical analysis}

Data are mean \pm standard deviation (SD) of the mean of two independent experiments performed in triplicate. Significance was assessed by one-way analysis of variance (ANOVA) followed by the Dunnett's test.

For neural network activity analysis data, the Student's one-tail paired $t$-test was performed to assess the differences between basal spontaneous activity and the activity after chemical exposure. Significance was set at $p<0.05$. The InStat and Prism software package (GraphPad Software, Inc.) were used.

\section{Results}

The data regarding the exposure threshold values for a single chemical compound, indicated by various international governments, often do not agree, and that the reported doses have a very wide range of variability, often referring to periods of time from short (i.e., 15 minutes) to longer exposures of a maximum of 8 hours corresponding to a working day, our tested samples were randomly taken from discarded mixtures to provide the potential risk for the workers at any time in a period of storage before its disposal.

\section{Cytotoxic effects}

To discriminate between inhibitory and cytotoxic effects, viability assays were performed on HeLa and HECV 2D cultures during their exposure to IM and OM random sampling.
The MTT and NR viability indexes obtained during exposure to OM of HeLa and HECV cells are reported in Figure 1A. After 4 hours, the MTT assay showed a marked susceptibility in the mitochondrial compartment in both HeLa and HECV cells exposed to $0.05 \%$ OM. Moreover, after 24 hours of OM treatment, the MTT results showed a further viability reduction of 52\% in the HeLa and $59 \%$ in HECV cultures compared with their respective untreated cultures. Exposure to OM did not affect the NR viability index in HeLa. By contrast, after 4 hours of treatment, the highest doses of OM induced a basal cytotoxicity in HECV reducing their viability of about $20 \%$. In addition, after 24 hours of $1 \%$ OM exposure, HECV viability decreased by $40 \%$ compared with untreated HECV.

A dramatic impairment in mitochondrial function was seen in both cell lines after exposure to IM, as shown in Figure 1B. MTT viability index was virtually zero in HeLa cells after as little as a 4-hour exposure to $0.5 \%$ and $1 \%$ concentrations and similar effects were detected at $0.25 \%$. HECV cells, during exposure to IM, reflected a time- and dose-dependent toxicity displaying worse membrane damage than HeLa cells. In fact, IM altered both the cell surface and the lysosomal membrane, and the NR viability index showed a threshold decrease in the HECV cultures. After a 4-hour exposure to $0.5 \%$ and $1 \%$ IM concentrations, as little as $37 \%$ and $16 \%$ of the HECV cells were viable, and after a 12- or 24-hour exposure, dose- and time-dependent toxicity effects were observed. Viability was no longer detectable in cells treated with $0.5 \%$ and $1 \%$ mixtures. The NR test showed a lower susceptibility of HeLa to IM with a $20 \%-$ $30 \%$ reduction at the highest dose $(1 \%)$ for a long exposure (12 and 24 hours).

\section{In vitro corrosion and irritation potential}

The RHE models' viability index decreased by $15 \%$ and $3 \%$ after a 3 - or 60-minute exposure to a corrosive positive chemical ( $8 \mathrm{~N} \mathrm{KOH}$ ) (Table 3$)$. In the OM-treated samples, viability resulted unchanged with respect to the negative control group at each exposure time. It was noted that IM was not corrosive after 3 minutes since the viability index was $90 \%$ compared with the controls. However, when the exposure was prolonged to 60 minutes, viability dropped to $3 \%$. According to OECD TG 431, IM is to be considered corrosive.

The exposure of RHE models to irritation-positive chemicals ( $5 \%$ sodium dodecyl sulphate) caused a generalized cell death, the viability index being near to $1 \%$ after a 42 -minute exposure up to 42 hours postincubation (Table 4). Under the same experimental conditions, OM only slightly affected viability, while the toxic effect of IM was higher, the viability index being $87 \%$ and $45 \%$ compared with the controls.

The prediction model for the SkinEthic RHE irritation and corrosion test method was performed according to OECD TG431 and 439, respectively, and the manufacturer's SOP. Irritation and corrosive potential were determined according to the EU CLP and UN GHS classification systems. $^{40,41}$ The test substance is considered a skin irritant (Category 2) if the mean relative viability after a 42-minute exposure and 42 hours postincubation is less or equal $(\leq)$ to $50 \%$ of the negative control. Test material is considered corrosive if the mean relative viability resulted less or 

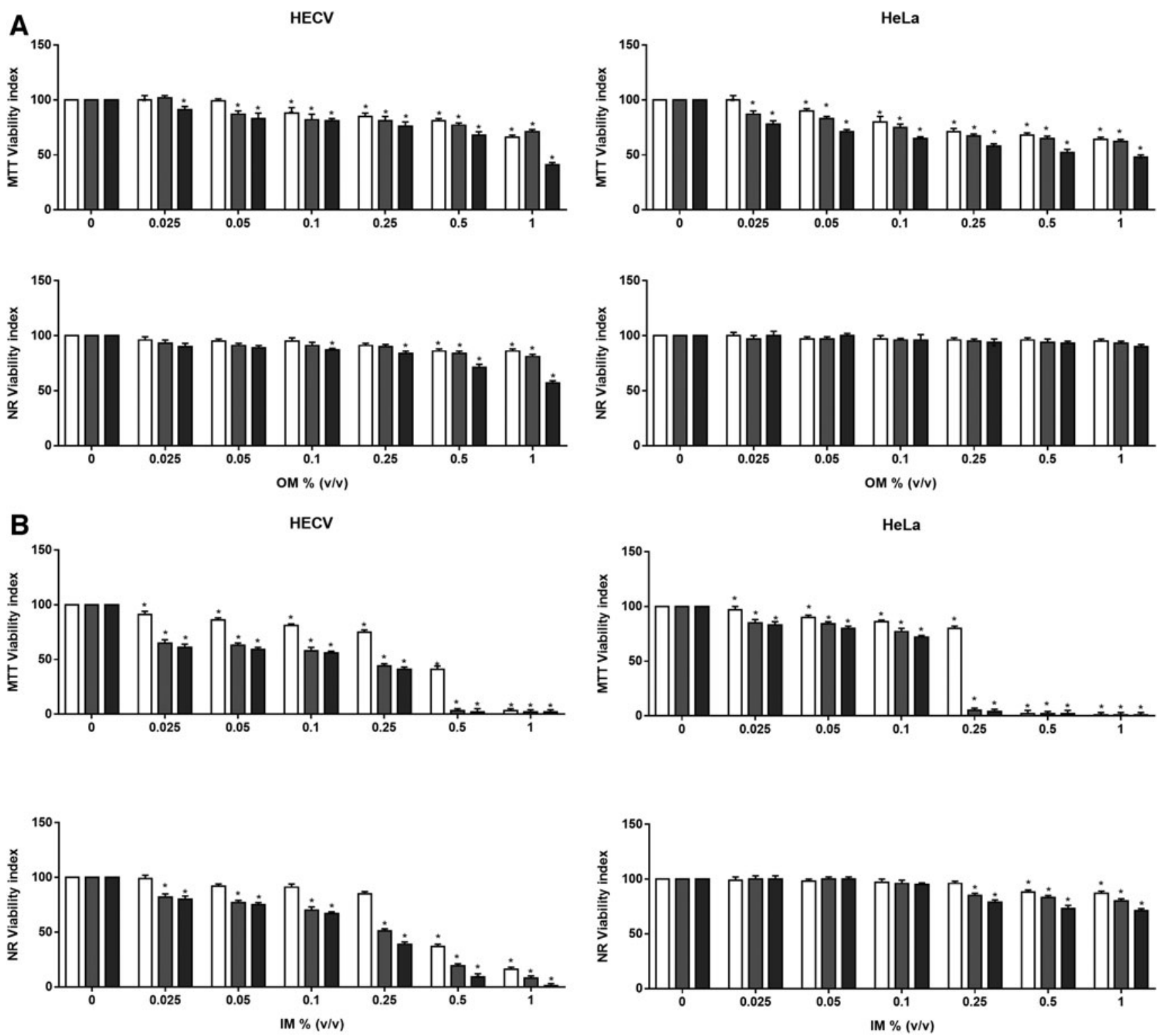

FIG. 1. MTT and NR viability index evaluation after exposure to OM (A) and IM (B). Viability index of HECV and HeLa cells was extrapolated by MTT and NR assays. HeLa and HECV cells were exposed to $0.025 \%, 0.05 \%, 0.1 \%, 0.25 \%, 0.5 \%$, and $1 \% \mathrm{OM}$ and IM for $4 \square, 12 \square$, and $24 \square$ hours. The values are the percentages versus the respective untreated cultures, representing the mean of two separate experiments performed in triplicate $\pm \mathrm{SD}$. $* p<0.01$ versus untreated cultures (ANOVA and Dunnett test). ANOVA, analysis of variance; IM, inorganic mixture; MTT, (4,5-dimethylthiazol-2-yl)-2,5diphenyltetrazolium bromide; NR, neutral red uptake; OM, organic mixture; SD, standard deviation.

equal $(\leq)$ to $35 \%$ after 3 minutes of exposure, or $\geq$ to $35 \%$ after 3 minutes of exposure and $<35 \%$ after a 60 - or 240 minute exposure.

In our study, based on the above indications, differently from OM, IM resulted to be both irritant and highly corrosive after 60 minutes on the 3D epidermis model (Tables 3 and 4).

\section{Gene expression of inflammation markers}

To assess whether the inflammatory pathway was triggered as a result of exposure to OM and IM, we analyzed the gene expression of two cytokines: TNF- $\alpha$, a typical early proinflammatory cytokine, and IL-18, an essential component of dermal sensitization. Hsp70 gene expression was also analyzed as an early warning bioindicator of cellular hazards and as a cellular stress response marker (Fig. 2). This analysis was carried out on HeLa cells, as representative of a first-contact target, after a 24-hour exposure of experimental treatments. Exposure to 4,20 , or $40 \mu \mathrm{g} / \mathrm{mL}$ of NiSO4, performed as a positive control, showed that IL-18 mRNA increased by $15 \%$ after 24 hours, while TNF- $\alpha$ gene levels decreased in a dose-dependent way. By contrast, Hsp70 mRNA was not affected by $\mathrm{NiSO}_{4}$.

OM did not induce any significant effect on IL-18 mRNA levels. In $0.05 \%$ and $1 \%$ OM-treated HeLa cells, TNF- $\alpha$ gene and Hsp70 showed opposite trends. TNF- $\alpha$ gene levels 
Table 3. In Vitro Corrosive Potential PREDictive IndEX

\begin{tabular}{lccl}
\hline & \multicolumn{3}{c}{ Corrosive potential } \\
\cline { 2 - 4 } Chemical & $\begin{array}{c}\text { Exposure } \\
\text { (minutes) }\end{array}$ & $\begin{array}{c}\text { Viability } \\
(\% \text { vs. NC) }\end{array}$ & Prediction \\
\hline $\mathrm{OM}$ & 3 & $107 \pm 1.7$ & Noncorrosive \\
& 60 & $100 \pm 0.1$ & Noncorrosive \\
$\mathrm{IM}$ & 3 & $90 \pm 4.4^{*}$ & Noncorrosive \\
& 60 & $3 \pm 1.4^{* *}$ & Cat. 1 \\
$\mathrm{PC}$ & 3 & $14 \pm 0.7^{* *}$ & Cat. 1 \\
& 60 & $2 \pm 1.9^{* *}$ & Cat. 1 \\
\hline
\end{tabular}

In vitro skin corrosion test using RHE models treated with OM and IM. The viability of human skin models treated with chemicals for 3 and 60 minutes was extrapolated by comparing the optical density of the formazan extracts measured at $570 \mathrm{~nm}$ in percentages compared with the negative controls. The prediction model for the SkinEthic ${ }^{\mathrm{TM}}$ RHE irritation test method was performed according to the OECD TG 431 and the EU CLP and UN GHS classification, in which corrosives (EU CLP/UN GHS Cat 1) are distinct from noncorrosives.

${ }^{*} p<0.05, * * p<0.001$ versus NC.

$\mathrm{NC}$, negative control $\left(\mathrm{H}_{2} \mathrm{O}\right)$; $\mathrm{PC}$, positive control $(8 \mathrm{~N} \mathrm{KOH})$; RHE, human-epidermis-reconstructed.

markedly increased by $23 \%$ and $56 \%$ compared with the untreated cultures, while Hsp70 reached levels of $20 \%$ lower than those of the control cells (Fig. 2).

The exposure to the lowest doses tested for IM $(0.25 \%)$ did not affect any selected gene. IL-18 gene levels showed a dose-dependent reduction, reaching significant values only for the highest dose of IM. TNF- $\alpha$ mRNA levels increased up to $75 \%$ after exposure to $0.5 \%$ IM and decreased up to $45 \%$ in $0.1 \%$ IM-treated cells compared with untreated cultures (Fig. 2). Hsp70 mRNA maintained its stable levels,

Table 4. IN Vitro Irritant Potential Predictive IndeX

\begin{tabular}{lccc}
\hline & \multicolumn{3}{c}{ Irritant potential } \\
\cline { 2 - 5 } Chemical & Exposure & $\begin{array}{c}\text { Viability } \\
(\% \text { vs. NC) }\end{array}$ & Prediction \\
\hline OM & $\begin{array}{c}42 \text { minutes }+42 \text { hours } \\
\text { postincubation }\end{array}$ & $87 \pm 4.2^{*}$ & No category \\
IM & $\begin{array}{c}42 \text { minutes }+42 \text { hours } \\
\text { postincubation }\end{array}$ & $45 \pm 1.3^{* *}$ & Cat. 2 \\
PC & $\begin{array}{c}42 \text { minutes }+42 \text { hours } \\
\text { postincubation }\end{array}$ & $1 \pm 0.1^{* *}$ & Cat. 2 \\
\hline
\end{tabular}

In vitro skin irritation test using RHE models treated with OM and IM. Cell viability was measured after 45 minutes of treatment of test materials and postincubation for 42 hours. The viability of human skin model treated with chemicals was extrapolated by comparing the optical density of the formazan extracts measured at $570 \mathrm{~nm}$ in percentages compared with the negative controls. The prediction model for the SkinEthic ${ }^{\mathrm{TM}}$ RHE irritation test method was performed according to the OECD TG 439 and the EU CLP and UN GHS classification, in which the irritant threshold level of a substance is based on its capacity in reducing cell viability equal to or below $50 \%$ (EU CLP/UN GHS Category 2). Conversely, no irritant substance is classified (no category).

$* p<0.05 ; * * p<0.001$ versus NC.

$\mathrm{NC}$, negative control (PBS); $\mathrm{PC}=5 \%$ SDS.

PBS, phosphate-buffered saline; SDS, sodium dodecyl sulphate. similar to those of the control cultures during exposure to all IM doses.

\section{ATP synthesis}

MTT assay indicated that mitochondrial function is impaired by both OM and IM, determining a corresponding decrease in bioenergetic functionality, and as a consequence, also a decrease in the cellular ATP content. Therefore, ATP synthesis was measured in bovine rod OS homogenates taken as a model to assess $\mathrm{F}_{\mathrm{o}} \mathrm{F}_{1}$-ATP synthase activity. A basal maximal activity of $0.48 \pm 0.060 \mu \mathrm{mol} / \mathrm{min} / \mathrm{mg}$ of protein was observed. When the OSs were incubated in the presence of IM for 5 minutes, a dose-dependent inhibition of ATP synthesis was observed at concentrations between $1 \%$ and $0.025 \%$, as shown in Table 5 . No change in cellular ATP levels was found after 5 minutes of exposure to OM, representative of an acute exposure (data not shown). Therefore, the OSs were subjected to a 240-minute incubation, representative of a long-term exposure, and then, the ATP synthesis was assayed. Under this latter condition, with the exposure to the same doses as above, OM inhibited the OS ATP production in an all-or-nothing manner, with a threshold value between $0.25 \%$ and $0.1 \%$ (Table 6 ).

\section{Neurotoxicity assessment}

Exposure of rat cortical neuron cultures to IM induced a significant inhibition on each parameter related to the spontaneous electrical activity (Fig. 3): MFR was blocked with an $\mathrm{IC}_{50}=0.26 \%$ and the bursting behavior was strongly compromised as demonstrated by the inhibition of MBR, MBD, \% Spikes_B, and MISI_B with the IC $_{50}$ values of $0.23 \%, 0.27 \%, 0.20 \%$, and $0.28 \%$, respectively. OM also inhibited the spontaneous electrical activity, affecting all parameters, and was considerably more effective than IM (Fig. 3): the $\mathrm{IC}_{50}$ for MFR blockade was $=0.70 \%$, while the $\mathrm{IC}_{50}$ values for MBR, MBD, \% Spikes_B, and MISI_B were $1.4 \%, 0.65 \%, 0.81 \%$, and $0.74 \%$, respectively.

\section{Discussion}

Compositions of waste chemical mixtures can be unknown, as is the likelihood of reactions and/or interactions among their elements. These must be considered possibly unstable, ${ }^{7}$ as new chemicals may be continually synthesized, leading to infinite toxicological interactions. The probability of such reactions can decrease or increase over time, rendering the actual toxicity of a single component not foreseeable when present in a mixture. The issue of human exposure to chemical mixtures, thereby including laboratory waste, has been the object of several studies. ${ }^{42,43}$ There is increasing concern about the potential adverse effects on human health of mixtures, in which interactions between substances simultaneously present are unknown. Accordingly, in 2012, the EC considered the issue of exposure to mixtures an increasing concern for the potential adverse effects of the interactions between substances present simultaneously in a mixture. Consequently, it was recommended to assess the toxicity of a mixture as a whole, if there is significant likelihood of human exposure and the actual composition is unknown. ${ }^{12}$ 


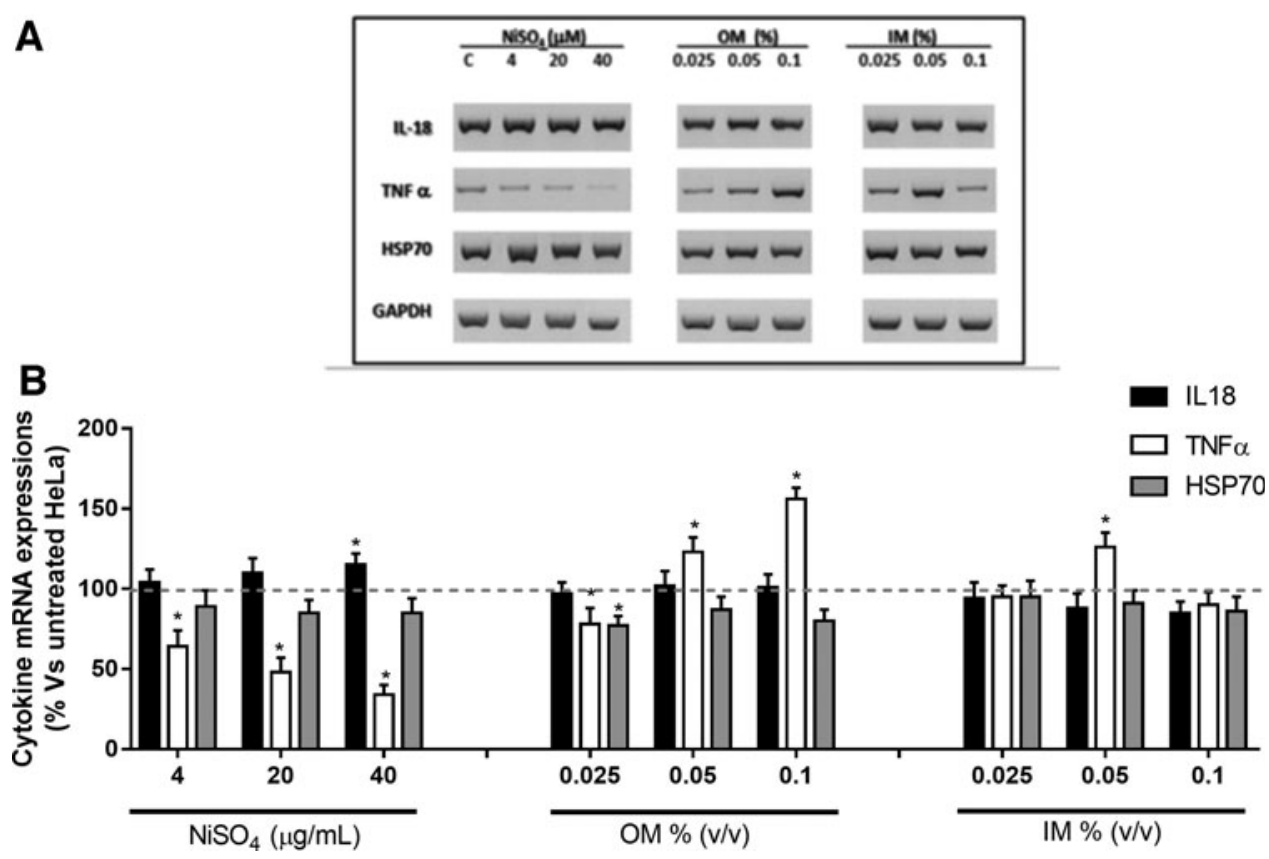

FIG. 2. mRNA levels of IL-18, TNF- $\alpha$, and HSP70. (A): The figures depicted are representative of at least three similar RT-PCR analysis of IL18, TNF- $\alpha$, HSP70, and GAPDH gene expressions in untreated and treated $\left(\mathrm{NiSO}_{4}, \mathrm{OM}\right.$, and IM) HeLa. (B) mRNA expressions of IL-18 and TNF- $\alpha$ proinflammatory cytokines and of HSP70, a marker of changes in cell resistance to acute stress, were analyzed by RT-PCR in HeLa cells after 24 hours of exposure to the positive control $\left(4-20-40 \mu \mathrm{g} / \mathrm{mL}\right.$ of $\left.\mathrm{NiSO}_{4}\right), \mathrm{IM}$, and $\mathrm{OM}(0.025 \%-0.05 \%-0.1 \%)$. The dotted red line represents the gene expressions of untreated HeLa. Data represent the mean \pm SD of two separate experiments in triplicate. ${ }^{*} p>0.01$ versus untreated cells (ANOVA followed by Dunnett's test). GAPDH, glyceraldehyde 3-phosphate dehydrogenase; IL-18, interleukin 18; RT-PCR, reverse transcription-polymerase chain reaction; TNF- $\alpha$, tumor necrosis factor-alpha.

The Regulatory Requirements and Guidance of Assessment of Mixtures also stated that, for a more predictive risk assessment of a mixture derived from environmental samples, it is better to assess the toxicity of the total mixture. .,10 $^{-10}$

Taking into account these considerations, as well as the lack of scientific data on the effect of laboratory chemical mixture waste on human health, ${ }^{2}$ here we tested the in vitro toxicity of IM and OM (CER $160506^{*}$ ) by an alternative in vitro multidimensional approach, in compliance with the 3Rs policy adopted by the EC.

We applied a multimodel in vitro approach to assess the toxicity of IM and OM to provide a unit prediction of the mixture instead of individual chemicals.

Today, despite the awareness of the need to implement alternative methods to animal testing (see REACH), ${ }^{40}$ also because the latter could result in inaccurate levels of predict-

TAble 5. EfFect of InORganic Mixture on RoD Outer Segment Adenosine Triphosphate Synthetic ABILITy

\begin{tabular}{lllllll}
\hline IM, \% & 1 & 0.5 & 0.25 & 0.1 & 0.05 & 0.025 \\
$\begin{array}{c}\text { ATP synthesis } \\
\text { inhibition, \% }\end{array}$ & 90 & 81 & 64 & 51 & 45 & 30 \\
\end{tabular}

This table reports ATP synthesis inhibition when OS suspensions $(0.04 \mathrm{mg} / \mathrm{mL})$ over 1 minute at $37^{\circ} \mathrm{C}$, and $\mathrm{pH} 7.3$ after preincubation for 5 minutes with IM at the indicated final concentrations. Control activity accounted for $0.48 \pm 0.04 \mu \mathrm{mol}$ ATP produced $/ \mathrm{min} / \mathrm{mg}$ of protein.

ATP, adenosine triphosphate; OS, outer segment. ability, more than often the use of laboratory animals is inevitable. On the contrary, alternative methodologies may sometimes require longer waiting periods of validation. Nevertheless, it is necessary to develop alternative tests rather than use the traditional in vivo methods for toxicity evaluation, considering that in vitro techniques also have the advantage of standardized testing conditions, reduced variability, and lower costs. Moreover, as it has been observed previously, despite the efforts invested in the last years in developing novel in vitro or in silico test systems, in vivo tests with rodents are still the only accepted test for neurotoxicity risk assessment at the EU regulatory level (OECD TG No. 424; OECD TG No. 426). ${ }^{44,45}$

The HeLa cells were selected because they represent the first point of contact with mixtures, ${ }^{30}$ and HECV endothelial cells are considered a suitable model to predict the toxicity of chemicals to the endothelium, if the skin barrier integrity is

Table 6. EfFect of Organic Mixture on Rod Outer Segment Adenosine Triphosphate SyNTHETIC ABILITy

\begin{tabular}{lllllll}
\hline OM, \% & 1 & 0.5 & 0.25 & 0.1 & 0.05 & 0.025 \\
$\begin{array}{c}\text { ATP synthesis } \\
\text { inhibition, \% }\end{array}$ & 80 & 78 & 18 & 13 & 10 & 6 \\
\end{tabular}

This table reports ATP synthesis inhibition when OS suspensions $(0.04 \mathrm{mg} / \mathrm{mL})$ over 1 minute at $37^{\circ} \mathrm{C}$, and $\mathrm{pH} 7.3$ after preincubation for 240 minutes with $\mathrm{OM}$ at the indicated final concentrations. Control activity accounted for $0.47 \pm 0.03 \mu \mathrm{mol}$ ATP produced $/ \mathrm{min} / \mathrm{mg}$ of protein. 


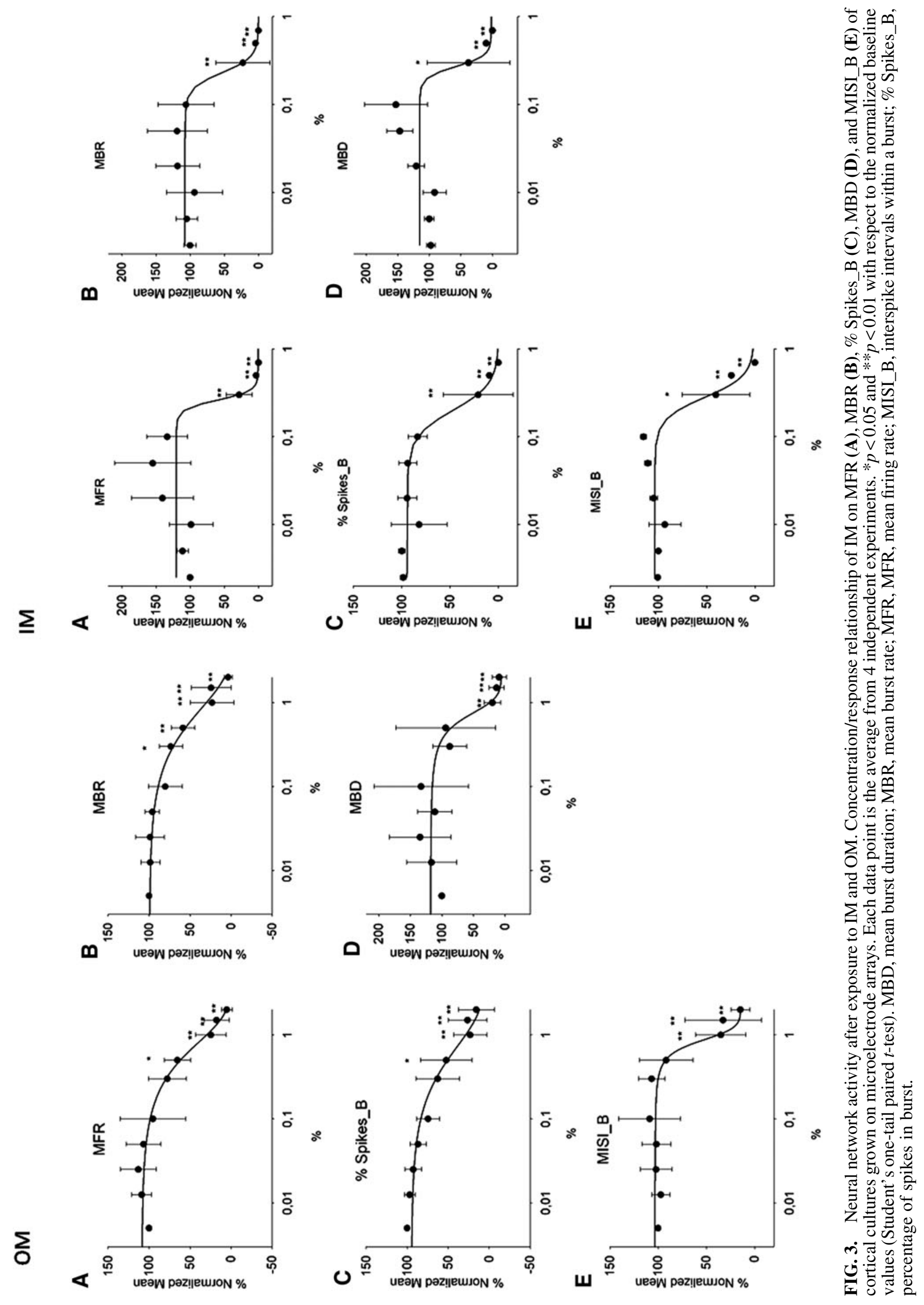


lost. In fact, while topic damage is the most direct, the most subtle effects are those on the nervous system (NS). The NS was shown to be particularly susceptible to many chemicals. $^{46-48}$ Considering the number of environmental contaminants with potential neurotoxic potential, neurotoxicity was also considered in our risk assessment.

Data show that IM displayed a more marked toxic effect than OM. In particular, IM represents a potential hazard for human skin, in line with the EU CLP and UN GHS classification systems. ${ }^{49}$ Exposure to $0.025 \%$ and $0.05 \%$ IM increased TNF- $\alpha$ mRNA levels, while at the highest tested dose a marked reduction was observed, suggesting the onset of inflammatory processes caused by increased cytokine protein synthesis. Furthermore, IM exposure seemed to trigger a sensitization pathway rather than a stress response, as the IL-18 gene, an essential component of dermal sensitization, ${ }^{50,51}$ showed a modulation in terms of decrement. Human keratinocytes produce IL-18, and it is considered a biomarker of contact allergens, as well as in in vitro models. ${ }^{52-56}$

After OM exposure, a marked increase in mRNA levels of TNF- $\alpha$ in the HeLa cells was observed in a dose-dependent way, while IL-18 gene expression remained almost constant (Fig. 2B). Exposure to OM apparently induced a resistance to stress in skin-derived cells: the observed decrease in Hsp70 mRNA levels could be related to an increased demand of its protein synthesis as a reaction to counteract the cell damage (Fig. 2B). In fact, Hsp70 is considered one the first markers induced by stressors. ${ }^{57}$ Accordingly, the NR viability index did not show any perturbation at the membrane level, and with the absence of irritation and corrosion potential as seen in the RHE models.

Inflammatory cytokines, such as TNF- $\alpha$ and IL-18, are secreted upon inflammasome activation in response to danger-associated molecular patterns (DAMPs), which include both microbial organisms and chemical stressors. Several DAMPs act through TNF- $\alpha$ signaling activating NALP1 (or NLRP1)-inflammasome. TNF- $\alpha$ might contribute to inflammasome-independent effects, inducing the expression of the high-affinity subunit of the IL-18 receptor. ${ }^{58,59}$ The NALP1-inflammasome is widely expressed and plays a pivotal role in skin diseases, thereby including contact hypersensitivity. ${ }^{60-62}$

NALP1-inflammasome maturation requires ATP, and exogenous ATP acts as a DAMP. ${ }^{63-65}$ Most inflammasome activators trigger variations in the extracellular ATP content. $^{66-68}$ IM and OM impaired mitochondrial function in both HeLa and HECV cells. This is consistent with recent evidence showing that inflammasome activation is accompanied by cellular homeostasis perturbations. Consistently, a molecular target of metabolic impairment from IM and OM appears to be the mitochondrion and the ATP synthase, here evaluated on the rod OS model that expresses the five complexes of respiration. ${ }^{37}$ An ectopic expression of ATP synthase appears widely distributed in many cellular membranes. ${ }^{37,69}$ The OS ATP synthase revealed a high level of susceptibility to exposure to both IM and OM (Fig. 1A, B; Tables 5 and 6). In particular, while IM was toxic, as shown by the clear dose/response elicited, the effect of the OM is quite aspecific. OM seems to affect the membrane coupling, impairing the ATP synthase, due to the solvents it contains, with a threshold above $0.5 \%$. Nonetheless, considering that the OS is a nervous tissue, the hypometabolism consequent to impairment of ATP synthase can be supposed to also contribute to the impairment of the nervous conduction in the rat cortical neuronal network. Notably, the dose/effect was similar.

Neurotoxicity of accidental exposure to IM or OM, evaluated as an impairment of spontaneous electrical activity of cortical neurons (Fig. 3), showed that IM that contains as $\mathrm{Hg}$ and hexavalent chromium, as well as nitric, sulfuric, and hydrochloric acids, strongly inhibited the spontaneous electrical activity of cortical neurons. In turn, OM heavily interfered with global spiking activity, confirming its higher toxicity. Exposure to xenobiotics such as heavy metals or pesticides was shown to lead to oxidative stress, which the brain is particularly vulnerable to. ${ }^{70}$ This is true especially during development, when the level of antioxidant enzymes is low in the face of a higher rate of oxygen consumption. Most neurotoxic chemicals generally belong to the following categories: metals, solvents, or pesticides, ${ }^{71}$ and therefore, the mixtures' object of the present study falls into all these categories. Neurotoxicological syndromes may manifest at a significantly later time and are often progressive or irreversible, with extensive health, social, and economic implications. Development and progression of many neurodegenerative diseases are related to hypometabolism ${ }^{72}$ and inflammation. ${ }^{73}$ In a neuroblastoma cell model, ATP released from dead cells activated the NALP1 inflammasome via TNF- $\alpha .{ }^{58}$

A study on human breast cancer reported a significant mixture effect for chemicals combined at concentrations that individually did not induce any observable androgen receptor antagonistic effect. ${ }^{74}$ A study on quantitative evaluation of human health hazard of human lymphoblast cell lines exposed to environmental pesticide mixtures conducted an in vitro-to-in vivo extrapolation to convert the in vitro cytotoxic concentrations to oral equivalent doses. It was found that a nominally more cytotoxic chlorinated pesticide mixture will have a greater safety margin than the current use pesticide mixture. $^{43}$

The present results highlight a real risk scenario for workers in chemical laboratories in terms of safety compliance. Exposure of humans to mixtures occurs often unintentionally. As required by safety rules, laboratory personnel who pour chemical from a laboratory into waste containers are subject to safety training and have access to chemical safety information. However, before removal, containers are stored in the laboratory for a considerable time, during which these are accessed continuously by users, possibly exposing them to gaseous by-products.

\section{Conclusions}

The potential toxicity of mixtures from waste containers where disposed chemical reagents are collected within the laboratory is still underestimated. The threshold doses of most hazardous chemicals of the tested mixtures resulted below the expected one stipulated by Italian regulations, and therefore, the exposure to such discarded mixtures should actually be not considered to be harmful. Also, dose limit ranges are often different from country to country. By contrast, the present preliminary in vitro multimodel approach showed that both OM and IM bear skin irritant and corrosive potential and can potentially cause bioenergetic impairments, as well as damage to neurons, activating inflammation. 
Much remains to be understood about the effect of the chemical mixtures studied and the mechanism of the toxicity they exert and we believe that further comprehensive studies can unveil a better clarification of such in the future, possibly by also extending a network action plan throughout the European Union and other countries.

\section{Acknowledgment}

The authors gratefully acknowledge Dr Massimiliano Brignone, CPG Lab Srl, Cairo Montenotte, Savona (Italy), for providing the chemical mixtures and related chemical certificates.

\section{Author Disclosure Statement}

No competing financial interests exist.

\section{Funding Information}

The study was partially funded by training projects relating to Research Grants in the PO CRO European Social Fund, Liguria Region 2007-2013, Axis IV "Human Capital” ob. specific 1/6 (DGR 1283/2011)_Project DPU12UNIGE83/500.

\section{References}

1. Araújo GL de, Campos MAA, Valente MAS, et al. Alternative methods in toxicity testing: The current approach. Braz J Pharm Sci 2014:50;55-62.

2. Barr DB, Buckley B. Assessing human exposure to environmental toxicants. In: Encyclopedia of Environmental Health. Amsterdam, The Netherlands: Elsevier; 2011, pp. 204-212.

3. Spurgeon DJ, Jones OAH, Dorne J-LCM, et al. Systems toxicology approaches for understanding the joint effects of environmental chemical mixtures. Sci Tot Environ 2010:408; 3725-3734.

4. Pistollato F, de Gyves EM, Carpi D, et al. Assessment of developmental neurotoxicity induced by chemical mixtures using an adverse outcome pathway concept. Environ Health 2020:19;23

5. Winneke G. Developmental aspects of environmental neurotoxicology: Lessons from lead and polychlorinated biphenyls. J Neurol Sci 2011:308;9-15.

6. Kim S-A, Lee Y-M, Choi J-Y, et al. Evolutionarily adapted hormesis-inducing stressors can be a practical solution to mitigate harmful effects of chronic exposure to low dose chemical mixtures. Environ Pollut 2018:233;725-734.

7. McQueen CA, Reilly C (ed). Respiratory Toxicology. 3rd ed. Amsterdam Boston Heidelberg London New York Oxford Paris San Diego San Francisco Singapore Sydney Tokyo: Elsevier; 2018.

8. Sarigiannis DA, Hansen U. Considering the cumulative risk of mixtures of chemicals-A challenge for policy makers. Environ Health 2012:11;S18.

9. Kienzler A, Bopp SK, van der Linden S, et al. Regulatory assessment of chemical mixtures: Requirements, current approaches and future perspectives. Regul Toxicol Pharmacol 2016:80;321-334.

10. Kienzler A, Berggren E, Bessems J, et al. Assessment of Mixtures: Review of Regulatory Requirements and Guidance. Luxembourg: Publications Office; 2014.

11. Ankley GT, Edwards SW. The adverse outcome pathway: A multifaceted framework supporting 21 st century toxicology. Curr Opin Toxicol 2018:9;1-7.
12. European Commission, Directorate General for Health \& Consumers. Toxicity and Assessment of Chemical Mixtures. Brussels: European Commission; 2012.

13. Wille JJ, Park JY. Induced differentiation of epithelioid carcinoma cell lines: Evidence for tumor cell quantal mitosis. J Cancer Ther 2016:7;794-811.

14. Puddu A, Sanguineti R, Traverso CE, et al. Response to anti-VEGF-A treatment of endothelial cells in vitro. Exp Eye Res 2016:146;128-136.

15. Romano P, Manniello A, Aresu O, et al. Cell Line Data Base: Structure and recent improvements towards molecular authentication of human cell lines. Nucleic Acids Res 2009: 37;D925-D932.

16. Izzotti A, Saccà SC, Di Marco B, et al. Antioxidant activity of timolol on endothelial cells and its relevance for glaucoma course. Eye 2008:22;445-453.

17. Amaroli A, Ravera S, Baldini F, et al. Photobiomodulation with $808-\mathrm{nm}$ diode laser light promotes wound healing of human endothelial cells through increased reactive oxygen species production stimulating mitochondrial oxidative phosphorylation. Lasers Med Sci 2019:34; 495-504.

18. Feng Y, Sanders AJ, Morgan LD, et al. In vitro significance of SOCS-3 and SOCS-4 and potential mechanistic links to wound healing. Sci Rep 2017:7;6715.

19. Sanders AJ, Owen S, Morgan LD, et al. Importance of activated leukocyte cell adhesion molecule (ALCAM) in prostate cancer progression and metastatic dissemination. Oncotarget 2019:10;6362-6377.

20. Kuhlmann I. The prophylactic use of antibiotics in cell culture. Cytotechnology 1996:19;95-105.

21. Nygaard UH, Niehues H, Rikken G, et al. Antibiotics in cell culture: Friend or foe? Suppression of keratinocyte growth and differentiation in monolayer cultures and 3D skin models. Exp Dermatol 2015:24;964-965.

22. Llobet L, Montoya J, López-Gallardo E, et al. Side effects of culture media antibiotics on cell differentiation. Tissue Eng C Methods 2015:21;1143-1147.

23. Skubis A, Gola J, Sikora B, et al. Impact of antibiotics on the proliferation and differentiation of human adipose-derived mesenchymal stem cells. IJMS 2017:18;2522.

24. Ryu AH, Eckalbar WL, Kreimer A, et al. Use antibiotics in cell culture with caution: Genome-wide identification of antibiotic-induced changes in gene expression and regulation. Sci Rep 2017:7;7533.

25. Singh R, Sripada L, Singh R. Side effects of antibiotics during bacterial infection: Mitochondria, the main target in host cell. Mitochondrion 2014:16;50-54.

26. Kandárová H, Liebsch M, Spielmann H, et al. Assessment of the human epidermis model SkinEthic RHE for in vitro skin corrosion testing of chemicals according to new OECD TG 431. Toxicol In Vitro 2006:20;547-559.

27. Kandárová H, Liebsch M, Schmidt E, et al. Assessment of the skin irritation potential of chemicals by using the SkinEthic Reconstructed Human Epidermal Model and the Common Skin Irritation Protocol Evaluated in the ECVAM Skin Irritation Validation Study. Altern Lab Anim 2006:34; 393-406.

28. OECD Test Guidelines for the Chemicals-OECD. http:// www.oecd.org/chemicalsafety/testing/oecdguidelinesforthe testingofchemicals.htm (last accessed April 27, 2020).

29. Borenfreund E, Puerner JA. Toxicity determined in vitro by morphological alterations and neutral red absorption. Toxicol Lett 1985:24;119-124. 
30. Faller C, Bracher M, Dami N, et al. Predictive ability of reconstructed human epidermis equivalents for the assessment of skin irritation of cosmetics. Toxicol In Vitro 2002:16;557-572.

31. Mosmann T. Rapid colorimetric assay for cellular growth and survival: Application to proliferation and cytotoxicity assays. J Immunol Methods 1983:65;55-63.

32. Cotovio J, Grandidier M-H, Lelièvre D, et al. In vitro assessment of eye irritancy using the Reconstructed Human Corneal Epithelial SkinEthic ${ }^{\mathrm{TM}}$ HCE model: Application to 435 substances from consumer products industry. Toxicol In Vitro 2010:24;523-537.

33. Jaiswal RK, Kumar P, Sharma A, et al. Proteomic identification of proteins differentially expressed following overexpression of hTERT (human telomerase reverse transcriptase) in cancer cells. PLoS ONE 2017:12; e0181027.

34. Wasson CJ, Zourelias JL, Aardsma NA, et al. Inhibitory effects of $405 \mathrm{~nm}$ irradiation on Chlamydia trachomatis growth and characterization of the ensuing inflammatory response in HeLa cells. BMC Microbiol 2012:12;176.

35. Schnetkamp PPM, Daemen FJM. Isolation and characterization of osmotically sealed bovine rod outer segments. In: Methods in Enzymology. Vol. 81; pp. 110-116. Elsevier; 1982.

36. Calzia D, Degan P, Caicci F, et al. Modulation of the rod outer segment aerobic metabolism diminishes the production of radicals due to light absorption. Free Radic Biol Med 2018:117;110-118.

37. Panfoli I, Calzia D, Bianchini P, et al. Evidence for aerobic metabolism in retinal rod outer segment disks. Int $\mathrm{J}$ Biochem Cell Biol 2009:41;2555-2565.

38. Alloisio S, Nobile M, Novellino A. Multiparametric characterisation of neuronal network activity for in vitro agrochemical neurotoxicity assessment. Neuro Toxicol 2015: 48;152-165.

39. Novellino A, Scelfo B, Palosaari T, et al. Development of micro-electrode array based tests for neurotoxicity: Assessment of interlaboratory reproducibility with neuroactive chemicals. Front Neuroeng 2011:4;4.

40. European Chemical Agency (ECHA). Guidance on the Application of the CLP Criteria. https://echa.europa.eu/ documents/10162/23036412/clp_en.pdf/58b5dc6d-ac2a-49109702-e9e1f5051cc5 (last accessed December 10, 2020).

41. United Nations (UN). Globally Harmonised System of Classification and Labelling of Chemicals (GHS) Seventh revised edition. New York and Geneva: United Nations; 2017.

42. Feron VJ, Cassee FR, Groten JP, et al. International issues on human health effects of exposure to chemical mixtures. Environ Health Perspect 2002:110;893-899.

43. Abdo N, Wetmore BA, Chappell GA, et al. In vitro screening for population variability in toxicity of pesticidecontaining mixtures. Environ Int 2015:85;147-155.

44. OECD. Test No. 424: Neurotoxicity Study in Rodents. OECD; 1997.

45. OECD. Test No. 426: Developmental Neurotoxicity Study. OECD; 2007.

46. Kim S, Hong S-H, Bong C-K, et al. Characterization of air freshener emission: The potential health effects. J Toxicol Sci 2015:40;535-550.

47. Mundy WR, Padilla S, Breier JM, et al. Expanding the test set: Chemicals with potential to disrupt mammalian brain development. Neurotoxicol Teratol 2015:52;25-35.

48. Sela H, Cohen H, Elia P, et al. Spontaneous penetration of gold nanoparticles through the blood brain barrier (BBB). J Nanobiotechnol 2015:13;71.
49. Alépée N, Grandidier M-H, Tornier C, et al. An integrated testing strategy for in vitro skin corrosion and irritation assessment using SkinEthic ${ }^{\mathrm{TM}}$ Reconstructed Human Epidermis. Toxicology In Vitro 2015:29;1779-1792.

50. Gibbs S, Corsini E, Spiekstra SW, et al. An epidermal equivalent assay for identification and ranking potency of contact sensitizers. Toxicol Appl Pharmacol 2013:272; 529-541.

51. Koutoulaki A, Langley M, Sloan AJ, et al. TNF $\alpha$ and TGF$\beta 1$ influence IL-18-induced IFN $\gamma$ production through regulation of IL-18 receptor and T-bet expression. Cytokine 2010:49;177-184.

52. Corsini E, Mitjans M, Galbiati V, et al. Use of IL-18 production in a human keratinocyte cell line to discriminate contact sensitizers from irritants and low molecular weight respiratory allergens. Toxicol In Vitro 2009:23; 789-796.

53. Galbiati V, Bianchi S, Martínez V, et al. NCTC 2544 and IL-18 production: A tool for the in vitro identification of photoallergens. Toxicol In Vitro 2014:28;13-17.

54. Galbiati V, Mitjans M, Lucchi L, et al. Further development of the NCTC 2544 IL-18 assay to identify in vitro contact allergens. Toxicol In Vitro 2011:25;724-732.

55. Bil W, van der Bent SAS, Spiekstra SW, et al. Comparison of the skin sensitization potential of 3 red and 2 black tattoo inks using interleukin-18 as a biomarker in a reconstructed human skin model. Contact Dermatitis 2018:79;336-345.

56. Galbiati V, Gibbs S, Roggen E, et al. Development of an in vitro method to estimate the sensitization induction level of contact allergens. Curr Protoc Toxicol 2018:75; 20.15.1-20.15.20.

57. Gupta SC, Sharma A, Mishra M, et al. Heat shock proteins in toxicology: How close and how far? Life Sci 2010:86; 377-384.

58. Álvarez S, Muñoz-Fernández MÁ. TNF-A may mediate inflammasome activation in the absence of bacterial infection in more than one way. PLoS One 2013:8;e71477.

59. Strowig T, Henao-Mejia J, Elinav E, et al. Inflammasomes in health and disease. Nature 2012:481;278-286.

60. Franchi L, Eigenbrod T, Muñoz-Planillo R, et al. The inflammasome: A caspase-1-activation platform that regulates immune responses and disease pathogenesis. Nat Immunol 2009:10;241-247.

61. Li W-W, Guo T-Z, Liang D, et al. The NALP1 inflammasome controls cytokine production and nociception in a rat fracture model of complex regional pain syndrome. Pain 2009:147;277-286.

62. Watanabe H, Gaide O, Pétrilli V, et al. Activation of the IL- $1 \beta$-processing inflammasome is involved in contact hypersensitivity. J Invest Dermatol 2007:127;1956-1963.

63. Chavarría-Smith J, Vance RE. The NLRP1 inflammasomes. Immunol Rev 2015:265;22-34.

64. de Rivero Vaccari JP, Dietrich WD, Keane RW. Activation and regulation of cellular inflammasomes: Gaps in our knowledge for central nervous system injury. J Cereb Blood Flow Metab 2014:34;369-375.

65. MacDonald JA, Wijekoon CP, Liao K-C, et al. Biochemical and structural aspects of the ATP-binding domain in inflammasome-forming human NLRP proteins: Biochemical and Structural Aspects of Human NLRP Proteins. IUBMB Life 2013:65;851-862.

66. Choi AJS, Ryter SW. Inflammasomes: Molecular regulation and implications for metabolic and cognitive diseases. Mol Cells 2014:37;441-448. 
67. Duncan JA, Bergstralh DT, Wang Y, et al. Cryopyrin/ NALP3 binds ATP/dATP, is an ATPase, and requires ATP binding to mediate inflammatory signaling. Proc Natl Acad Sci 2007:104;8041-8046.

68. Ramani V, Awasthi S. Toll-like receptor 4-interacting SPA4 peptide suppresses the NLRP3 inflammasome in response to LPS and ATP stimuli. J Leukocyte Biol 2015:98; 1037-1048.

69. Panfoli I, Calzia D, Ravera S, et al. Extramitochondrial tricarboxylic acid cycle in retinal rod outer segments. Biochimie 2011:93;1565-1575.

70. Rock KD, Patisaul HB. Environmental mechanisms of neurodevelopmental toxicity. Curr Environ Health Rep 2018:5; $145-157$.

71. Grandjean P, Landrigan P. Developmental neurotoxicity of industrial chemicals. Lancet 2006:368;2167-2178.

72. Kljajevic V, Grothe MJ, Ewers M, et al. Distinct pattern of hypometabolism and atrophy in preclinical and predementia Alzheimer's disease. Neurobiol Aging 2014:35; 1973-1981.

73. Costas M, Trapp T, Pereda MP, et al. Molecular and functional evidence for in vitro cytokine enhancement of human and murine target cell sensitivity to glucocorticoids.
TNF-alpha priming increases glucocorticoid inhibition of TNF-alpha-induced cytotoxicity/apoptosis. J Clin Invest 1996:98;1409-1416.

74. Orton F, Ermler S, Kugathas S, et al. Mixture effects at very low doses with combinations of anti-androgenic pesticides, antioxidants, industrial pollutant and chemicals used in personal care products. Toxicol Appl Pharmacol 2014:278; 201-208.

Address correspondence to: Dr. Stefania Vernazza General Pathology Section Laboratory of Analysis and Research in Physiopathology (LARF) Department of Experimental Medicine University of Genoa Via L.B. Alberti 2 Genoa 16132 Italy

E-mail: stefania.vernazza@yahoo.it 